\title{
Promoting School Earthquake Safety through a Classroom Education Grass- roots Approach
}

\section{Dr. Lelli Van Den Einde, University of California, San Diego}

Van Den Einde is a Teaching Professor in Structural Engineering at UC San Diego. She incorporates education innovations into courses (Peer Instruction, Project-based learning), prepares next generation faculty, advises student organizations, hears cases of academic misconduct, is responsible for ABET, and is committed to fostering a supportive environment for diverse students. Her research focuses on engagement strategies for large classrooms and developing K-16 curriculum in earthquake engineering and spatial visualization.

\section{Ms. Heidi A. Tremayne, Earthquake Engineering Research Institute}

Heidi Tremayne is the Program Manager at Earthquake Engineering Research Institute (EERI). In this role, she is responsible for managing multiple projects and programs, creating and leading professional development programs, and supporting the Institute's committees and chapters. Notably, she is the lead staff member for EERI's flagship Learning From Earthquake program, as well as its new School Earthquake Safety Initiative. In her role at EERI, she utilizes both her engineering skills (she is a licensed California Civil Engineer) and management skills to help EERI members and volunteers take action to reduce earthquake risk.

\section{Dr. Thalia Anagnos, San Jose State University}

Dr. Thalia Anagnos is the Associate Vice President of Graduate and Undergraduate Programs at San Jose State University, where she has taught since 1984. She is a past-president of the Earthquake Engineering Research Institute, and from 2009 to 2014 she served as co-Leader of Education, Outreach, and Training (EOT) for the George E. Brown, Jr. Network for Earthquake Engineering Simulation (NEES), a consortium of 14 large-scale earthquake engineering experimental facilities.

\section{James Mallard, UC San Diego}




\title{
Promoting School Earthquake Safety through a Classroom Education Grassroots Approach
}

\begin{abstract}
The earthquake engineering community has recognized that in seismically active regions throughout the United States, hundreds of thousands of students and staff unknowingly study and work in structurally vulnerable school and university buildings. The School Earthquake Safety Initiative (SESI), spearheaded by the Earthquake Engineering Research Institute (EERI), is a collaborative network of diverse, expert, and impassioned professionals who are committed to creating and sharing knowledge and tools that enable broadminded, informed decision making around school earthquake safety. The Classroom Education and Outreach Subcommittee of SESI is tackling the problem of school safety from a grassroots approach, with the goal of using education in the classroom to create on ongoing dialog with parents, teachers, and administrators thereby developing advocates for earthquake school safety. To do so, well-defined K-12 engineering curriculum aligned with standards that are well documented and can be easily taught to a range of teachers for broad dissemination have been developed for $4^{\text {th }}$ grade and high school physics classes. The modules lead students through hands-on and research activities to learn basic earthquake engineering design principles and make use of an electronic instructional shaking table that allows students to test structures under representative earthquake loading. In an effort to reach a large number of schools across the country, the initiative is engaging regional professional and university student chapters to work closely with classroom teachers and collaborate on delivering the activities.
\end{abstract}

\section{Introduction}

In seismically active regions throughout the United States, hundreds of thousands of students and staff unknowingly study and work in structurally vulnerable school and university buildings. According to the U.S. Census ${ }^{[1]}$, approximately 71.5 million students are enrolled in K-12 schools as of fall 2015. These students attend public and private schools housed in buildings of varying seismic safety ranging from modern structures designed to the latest codes to older vulnerable structures of unreinforced masonry or nonductile concrete. No federal agency governs school building design, thus schools are built according to local codes and construction practices that vary significantly from region to region. Occupants of vulnerable facilities can be exposed to risks ranging from nonstructural falling hazards (e.g. lighting fixtures, ceiling tiles, partitions, furnishings, or ductwork) to partial or complete collapse of buildings. Furthermore, earthquakes can generate landslides and tsunamis that can damage facilities as well as hamper evacuation.

While seismic risks posed by all vulnerable structures should be mitigated, Wolf and Yang ${ }^{[2]}$ note that three characteristics of school buildings elevate their priority for retrofit:

- First, schools are the only high occupancy public buildings other than prisons and courthouses whose occupants are compelled by legal mandate to be inside them. 
- Second, school buildings in many communities tend to remain in use longer than comparable structures in private ownership, and tend to receive less frequent and less consistent capital renewal investment.

- Third, community members and public officials often hold a high (if unfounded) expectation that schools will provide community shelter or host public services in the wake of a natural disaster.

Furthermore, students are a vulnerable population who have not yet developed the critical thinking skills to consent to and accept risks, so they rely on adults to protect their safety. Numerous government agencies, state seismic safety commissions, seismic safety policy organizations, researchers, professional engineering organizations, school districts, and parent/teacher associations have recognized the threat posed by vulnerable schools. A 2012 report from the Advisory Committee on Earthquake Hazards Reduction (ACEHR) of the National Earthquake Hazards Reduction Program (NEHRP) ${ }^{[3]}$ recommended that "School children have a right to learn in buildings that are safe from natural hazard events." The report includes eight recommended actions for the Federal Emergency Management Agency (FEMA) including stipulating safety performance standards for school buildings, updating curriculum to educate students on natural hazards and risk reduction measures, and reviewing the condition of all existing school buildings and mitigating documented vulnerabilities.

As part of its strategic plan the Earthquake Engineering Research Institute (EERI) has committed to taking a leadership role in promoting earthquake safety in schools. EERI is a multidisciplinary national society of nearly 3000 engineers, geoscientists, building officials, architects, planners, public officials, social scientists and students dedicated to advancing the science and practice of earthquake engineering and reducing the impacts of earthquakes on society. EERI's School Earthquake Safety Initiative (SESI) aims to engage the EERI membership and other experts in creating and sharing knowledge and tools that enable broadminded, informed decision making around school earthquake safety ${ }^{[4]}$. The goal of the effort is to leverage the earthquake engineering community's extensive expertise to promote and conduct regionally appropriate actions that make a substantial and positive difference in communities around the world, by protecting the lives of all who inhabit school buildings ${ }^{[5]}$. SESI is led by an executive committee that coordinates the work of five subcommittees: 1) Safety Screening, Inventory, and Evaluation of Schools, 2) Classroom Education and Outreach, 3) Tsunami Mitigation for Schools, 4) Code Updating and Improvements, 5) Safety Advocacy and Messaging.

The Classroom Education and Outreach Subcommittee is tackling the problem of school safety from a grassroots approach, with the goal of using education in the classroom to create ongoing dialog with parents, teachers, and administrators thereby developing advocates for earthquake school safety. As has been demonstrated with the Great Southern California ShakeOut and the Dare to Prepare campaign, consistent and simple messaging is an effective way to help the public understand how to be safe in an earthquake and to take action to prepare for future events $^{[6]}$. The SESI Classroom and Outreach Subcommittee plans to use a similar approach to help students, teachers, administrators, and parents become aware of the seismic risks in their schools. 


\section{Curriculum}

Well-defined K-12 engineering curriculum aligned with standards that are well documented and can be easily taught to a range of teachers for broad dissemination have been developed for $4^{\text {th }}$ grade and high school physics classes. Both the $4^{\text {th }}$ and high school curricula lead students through hands-on and research activities to learn basic earthquake engineering design principles such as the effects of earthquake-resisting elements like diagonal bracing and shear walls. They make use of an electronic instructional shaking table that tests structures under representative earthquake loading. The $4^{\text {th }}$ grade project requires students to build $\mathrm{K}^{\prime} \mathrm{Nex}^{\mathrm{TM}}$ buildings while the high school physics project consists of two-story balsa wood structures and integrates mathematical predictions into a design competition.

\section{1. $4^{\text {th }}$ Grade Curriculum}

\subsubsection{Initial lesson development at NEES@Berkeley}

The EERI SESI outreach program leverages curriculum for $4^{\text {th }}$ grade students that was developed over a span of approximately seven years (from 2007-2014) at the University of California, Berkeley. As part of the Network for Earthquake Engineering Simulation (NEES) education and outreach program, the structural laboratories at UC Berkeley (NEES@Berkeley) received funding from the National Science Foundation to develop meaningful programs for students in the local communities surrounding the university and its off-site laboratories. Building on staff expertise at NEES@Berkeley and its focus on structural engineering, the outreach activities were designed and developed as hands-on lessons using small educational shaking tables and $\mathrm{K}^{\prime} \mathrm{Nex}^{\mathrm{TM}}$ materials ${ }^{[7]}$. A part-time staff coordinator ran the program with the support of hired undergraduate and graduate student instructors who worked part-time delivering the lessons ${ }^{[8][9]}$. The goal of this outreach from its initiation was to foster enthusiasm in the science of earthquakes and earthquake engineering, expose the students to earthquakes in an exciting, hands-on, interactive environment, and activate student interest in STEM while engaging curiosity and creativity.

After approximately five years of informal outreach using these materials with kindergarten to $12^{\text {th }}$ grade students, in 2013 the NEES@Berkeley staff expanded and refined their lessons to align with California Science Standards. With the help of an educational curriculum specialist from a local non-profit, Community Resources for Science (CRS) ${ }^{[10]}$, K-12 teachers piloted lessons and provided guidance on appropriate vocabulary, supplemental worksheets, and delivery strategies to optimize implementation in the classroom. The pilot lessons focused on $4^{\text {th }}$ grade students because the California Standards and the Next Generation Science Standards (NGSS) ${ }^{[11]}$ at this grade level specifically address earthquakes and their impacts on society. Table 1, an excerpt from "Earthquake Engineering Design Lesson Summary \& Curriculum Mapping" provided in the NEES@Berkeley lesson documentation ${ }^{9}$, shows the mapping of the lesson onto both the California Standards and the proposed Next Generation Science Standards at the time of development in 2013. The NGSS for $4^{\text {th }}$ grade specifically suggests designing earthquake resistant buildings as a way to meet standard "4-ESS3-2: Generate and compare multiple solutions to reduce the impacts of natural earth processes on humans." The updated lesson unit was launched to teachers in Fall 2013 and included the following components and features: 
- Hands-on, collaborative learning experiences and a design challenge that teaches students the engineering design process for an earthquake resistant building.

- Two 90-minute classroom visits by university engineering student instructors who lead the learning experience by providing instruction, demonstrations, and materials for the hands-on activities.

- Integrated engineering skill development as described in the Next Generation Science Standards

- An optional field trip to the earthquake engineering laboratory at UC Berkeley's Richmond Field Station to see engineering in action, with a fully-funded bus provided.

- Free copy of the materials and lesson plans to participating teachers to support independent teaching of this unit in the future.

\section{Table 1: Sample Documentation for $4^{\text {th }}$ Grade Curriculum}

\begin{tabular}{|c|c|}
\hline $\begin{array}{l}\text { Student Learning } \\
\text { Objectives: }\end{array}$ & $\begin{array}{l}\text { Students will: } \\
\text { - Learn that earthquakes are a natural hazard and engineers help design buildings to } \\
\text { - } \text { reduce damage. } \\
\text { - } \quad \text { Giscover what building elements affect building stability. } \\
\text { - Understand that study of failure mechanisms can be used to improve design. } \\
\text { - } \quad \text { Experience the engineering design process, including: } \\
\text { - defining design problems, } \\
\text { - using fair tests to collaboratively produce data, } \\
\text { - comparing alternate solutions with design criteria, and } \\
\text { - communicating evidence-based recommendations. }\end{array}$ \\
\hline $\begin{array}{l}\text { Related California } \\
\text { State Standards: }\end{array}$ & $\begin{array}{l}4^{\text {th }}-\text { Earth Science } \\
\text { There are slow and rapid processes that change the Earth (erosion, landslide, volcanoes, } \\
\text { earthquakes) } \\
\frac{4^{\text {th }}-\text { Investigation and Experimentation }}{\text { a. differentiate observation from inference (interpretation), and know that scientists' }} \\
\quad \text { explanations come partly from what they observe and partly from how they interpret } \\
\text { their observations. } \\
\text { c. formulate and justify predictions based on cause and effect relationships. } \\
\text { d. conduct multiple trials to test a prediction and draw conclusions about the relationships } \\
\text { between results and predictions. } \\
\text { f. follow a set of written instructions for a scientific investigation. }\end{array}$ \\
\hline $\begin{array}{l}\text { Related Next } \\
\text { Generation Science } \\
\text { Standards (NGSS) } \\
\text { proposed for } \\
\text { California: }\end{array}$ & $\begin{array}{l}4^{\text {th }} \text { - Earth's Systems: Processes that Shape the Earth } \\
\text { 4-ESS2-2 Analyze and interpret data from maps to describe patterns of Earth's features. } \\
\text { Clarification: Maps can include topographic maps of Earth's land and ocean floor, as well } \\
\text { as maps of the locations of mountains, continental boundaries, volcanoes, and earthquakes. } \\
\text { 4-ESS3-2 Generate and compare multiple solutions to reduce the impacts of natural Earth } \\
\text { processes on humans. } \\
\text { Clarification: Examples of solutions could include designing an earthquake resistant } \\
\text { building and improving monitoring of volcanic activity. } \\
\text { Engineering Design } \\
\text { 3-5-ETS1-1 Define a simple design problem reflecting a need or a want that includes } \\
\text { specified criteria for success and constraints on materials, time or cost. } \\
\text { 3-5-ETS1-2 Generate and compare multiple possible solutions to a problem based on how } \\
\text { well each is likely to meet the criteria and constraints of the problem. } \\
\text { 3-5-ETS1-3 Plan and carry out fair tests in which the variables are controlled and failure }\end{array}$ \\
\hline
\end{tabular}


Additional description and resources related to this $\mathrm{K}^{\text {' }} \mathrm{Nex}^{\mathrm{TM}}$ structure design activity can be found in the educational resources in NEESacademy on the NEES website ${ }^{[12]}$, Pacific Earthquake Engineering Research Center (PEER) website ${ }^{[9]}$ and in a paper ${ }^{[7]}$.

During the 2013-2014 school year, these updated lessons were launched at eleven 4th grade classrooms located in eight schools in Oakland, Berkeley and Richmond, California. Two teacher-training workshops were also held to introduce the teachers to the curriculum. Figure 1 shows the shaking table component of the activity underway at the NEES@Berkeley labs.

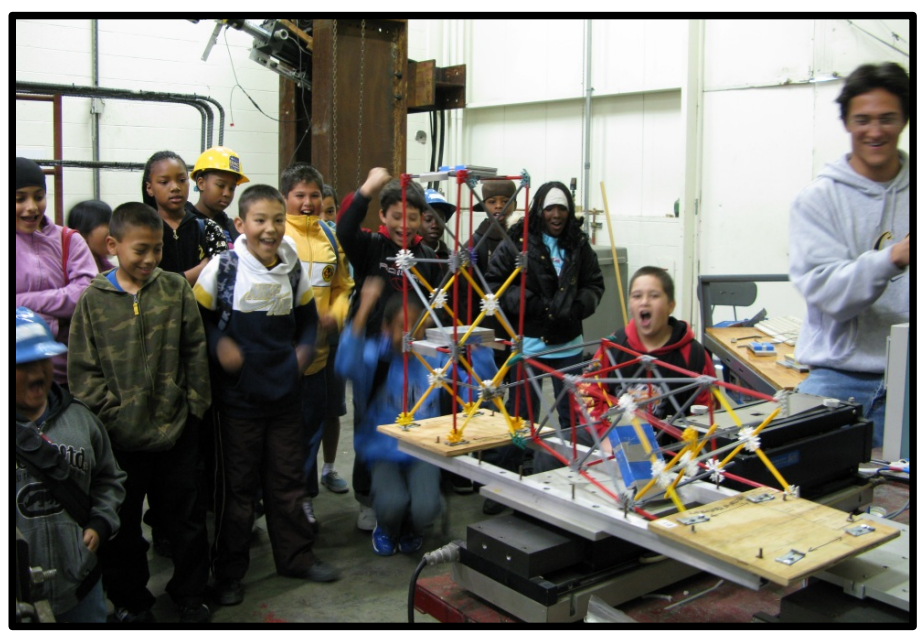

Figure 1: Students testing K'Nex ${ }^{\mathrm{TM}}$ structures on an electronic shaking table at the NEES@Berkeley labs

The success of the NEES@Berkeley outreach program was assessed throughout its duration with survey forms delivered to participating teachers (see Figure 2). Questions in the form include both formative evaluations to find areas for improvement, as well as summative assessment to get an estimate of the learning outcomes achieved by the participating students. In 2014, as the program ended for NEES@Berkeley, the assessment form was also updated by Community Resources for Science to align with the new updated curriculum developed by CRS $^{[13]}$.

Results from these updated forms are not available for 2014, however a prior version of the form used to assess the program from 2010-2012 yielded teacher rankings (averaged over 30 participating teachers) of 5.0 for the $\mathrm{K}^{\prime} \mathrm{Nex}^{\mathrm{TM}}$ activity, and 4.7 for the overall program based on a $1-5$ rating scale $e^{[7]}$.

\subsubsection{EERI SESI 4th Grade Lesson Overview and Modifications from NEES@Berkeley Versions}

In 2014, the Earthquake Engineering Research Institute decided to launch SESI. By early 2015, the Classroom Education Subcommittee was formed and decided to utilize existing curriculum that aligned with relevant educational standards. The NEES@Berkeley $4^{\text {th }}$ grade lessons were a perfect fit due to their thorough documentation, focus on earthquakes, and alignment with the California and NGSS standards. 


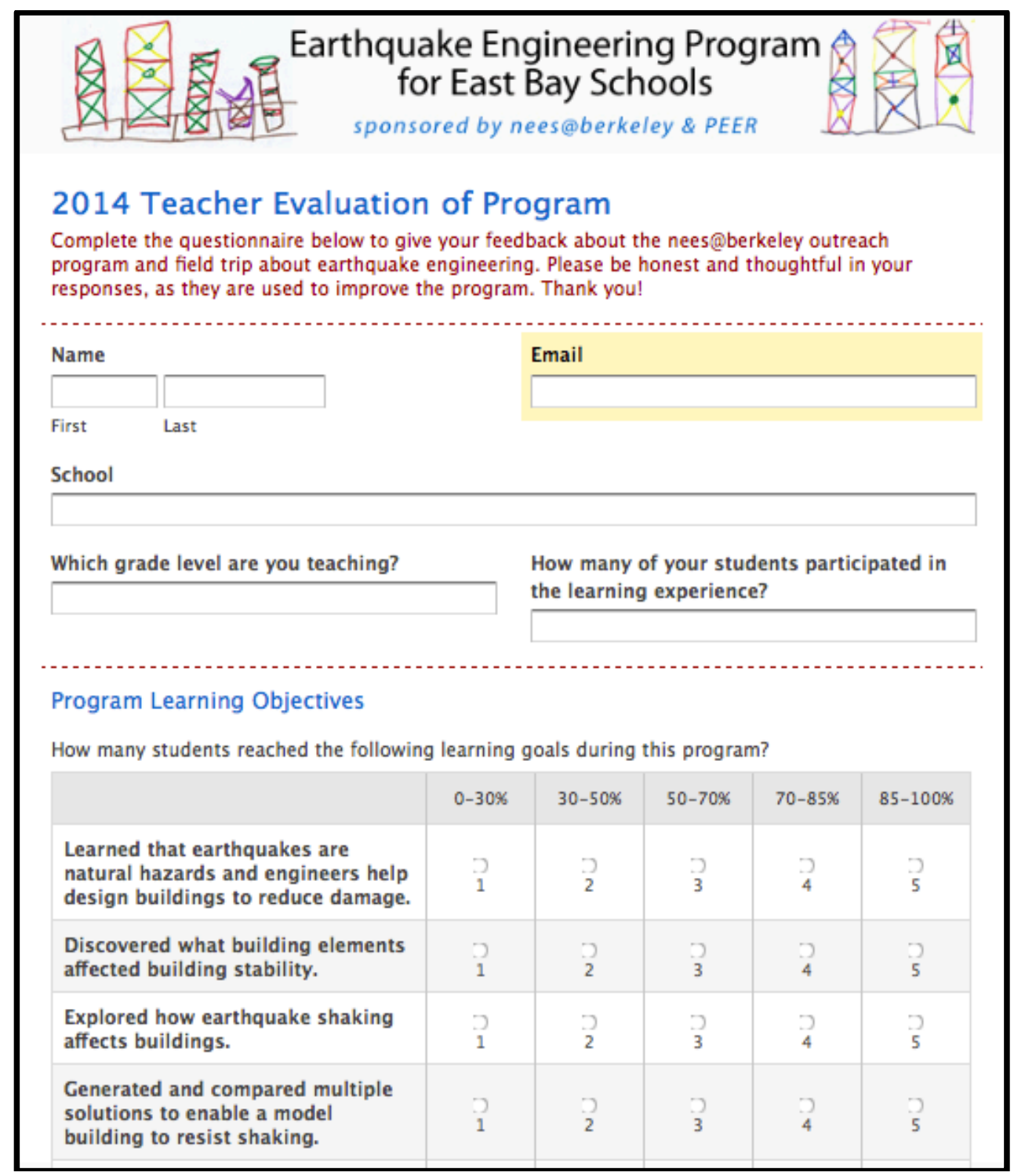

Figure 2: Image of survey form delivered to teachers participating in the 2014 program $^{[13]}$

The EERI SESI $4^{\text {th }}$ grade lesson reflects closely the NEES@Berkeley with some modifications to the timing of various lesson components. In addition, modifications were made to accommodate the variety of educational shaking tables used in the SESI program. The following description is extracted from the lesson materials developed by the PEER \& NEES@Berkeley Education Program and modified by SESI from July 2015 to January $2016^{[14]}$.

The first 90-minute lesson introduces earthquakes, the engineering process, and design elements which are then tested by the students to develop ideas for strengthening buildings. This experience provides support for:

- Learning that engineering is driven by needs and wants

- Learning about realistic model development as part of the design process as students work with shaking variables and $\mathrm{K}^{\prime} \mathrm{Nex}^{\mathrm{TM}}$

- Constructing a "fair" test with controlled variables, multiple runs, etc. 
- Learning to observe "failure points" and "failure mechanisms" as a source of information

- Drawing specific evidence-based conclusions about design element testing

- Analyzing and interpreting data from element testing using logical reasoning

- Introducing earthquakes as a natural Earth process with impacts for humans

- Interpreting earthquake information from maps

Scaffolding is provided through visuals of vocabulary and demonstrations, using a "say it/show it/write it" approach for instructions, and sentence framing on the worksheets to help students focus on key observations and develop background knowledge.

The second 90-minute lesson provides students with the challenge of designing an earthquakeresistant building and presenting their data to make a group decision about selecting among different approaches to reach a design solution. Students work collaboratively in six design teams, to learn structural engineering vocabulary, define specific criteria and limitations for an earthquake-resistant building, test and refine their designs, collect data, and communicate their findings. This experience provides support for:

- Learning how to define a design problem in terms of success criteria and constraints

- Planning and carrying out "fair tests" of different approaches

- Making observations to produce data to test a design solution

- Using failure points to identify aspects of a model that could be improved

- Generating multiple possible solutions and comparing with design criteria and constraints

- Analyzing data from tests to identify best characteristics that can be combined

- Identifying evidence to support recommendations to the full design group

- Presenting evidence in writing and orally

Scaffolding is provided through review of vocabulary for design elements using actual building materials, visual and verbal review of the results of the design element testing, group work on design challenges and conclusions, prompts for team work and evidence-based conclusions, and guidelines for discussion.

\subsection{High School Curriculum}

The high school SESI curriculum targets very similar learning objectives as the $4^{\text {th }}$ grade curriculum that was outlined in Table 1. It begins with preliminary concept lectures, demonstrations utilizing a small instructional shaking table, and a concept research assignment. Furthermore, it features the design, construction, analysis, and testing of a balsa model structure (BMS). Specifically, the students retrofit a BMS to include a lateral force resisting system (LFRS) that includes a combination of diagonal bracing, shear walls, and gusset plates. After constructing their model, students are tasked to predict its dynamic behavior. These predictions are compared to the observed behavior when their BMS is tested on an instructional shaking table under three earthquake records of increasing intensity. The curriculum is designed to include four 60 minute visits to the high school classroom by EERI student chapter and local professional members, but can be extended into more visits depending on the high school's availability. The project has been developed as a team competition where students optimize their design to achieve the highest performance index (PI). 
The high school curriculum satisfies Common Core mathematics standards related to the modeling cycle involving (1) identifying variables, (2) formulating a model, (3) analyzing and performing operations on these relationships to draw conclusions, (4) interpreting the results, (5) validating the conclusions, and (6) reporting on the conclusions and the reasoning behind them. Students apply geometric concepts in modeling situations in order to solve design problems (e.g., designing an object or structure to satisfy physical constraints or minimize cost). Furthermore, English Language Arts (ELA) standards related to speaking, listening, writing and research skills are also incorporated. For example, ELA standards relating to following complex multistep procedures when carrying out experiments, analyzing results based on explanations in the text, and determining the meaning of symbols, key terms, and other domain-specific words and phrases as they are used in a specific scientific or technical context are met through this high school curriculum.

The curriculum is also aligned closely with the NGSS standards, specifically the engineering design requirements (HS-ETS1), as summarized below.

- HS-ETS1-1: Analyze a major global challenge to specify qualitative and quantitative criteria and constraints for solutions that account for societal needs and wants.

- HS-ETS1-2: Design a solution to a complex real-world problem by breaking it down into smaller, more manageable problems that can be solved through engineering.

- HS-ETS1-3: Evaluate a solution to a complex real-world problem based on prioritized criteria and trade-offs that account for a range of constraints, including cost, safety, reliability, and aesthetics as well as possible social, cultural, and environmental impacts.

- HS-ETS1-4: Use a computer simulation to model the impact of proposed solutions to a complex real-world problem with numerous criteria and constraints on interactions within and between systems relevant to the problem.

The framework for this curriculum is based on a comprehensive dynamic and mathematical analysis of a previously designed balsa wood structure (reference model) that was built as part of curriculum for the California State Summer School for Mathematics and Science (COSMOS), an academic summer camp at UC San Diego ${ }^{[15]}$. Analysis of this structure's response included the determination of the reference model's mass, stiffness, and damping ratio along with the formation of the structure acceleration time history, the response spectrum, and the frequency content for three earthquake records. In the SESI curriculum students use this mathematical model to predict the response of their BMS and to learn earthquake engineering concepts.

\subsubsection{Preliminary Concept Lectures}

The first of two lectures focuses on the basics of structural engineering and introduces the demands that earthquakes impose on structures, while the second lecture highlights earthquake engineering in detail.

The lecture on structural engineering basics is devoted to highlighting fundamental structural engineering concepts and the profession's importance to society. Specifically, students are taught the concepts of structural capacity and demand and how they serve as the basis for analysis of structural safety. The lecture concludes with contextual information on characteristics of earthquake motion such as the different seismic waves and examples of earthquake damage in 
the form of photographs showing the consequences of earthquakes on structures from past seismic events. Example slides from Lecture 1 are shown in Figure 3.

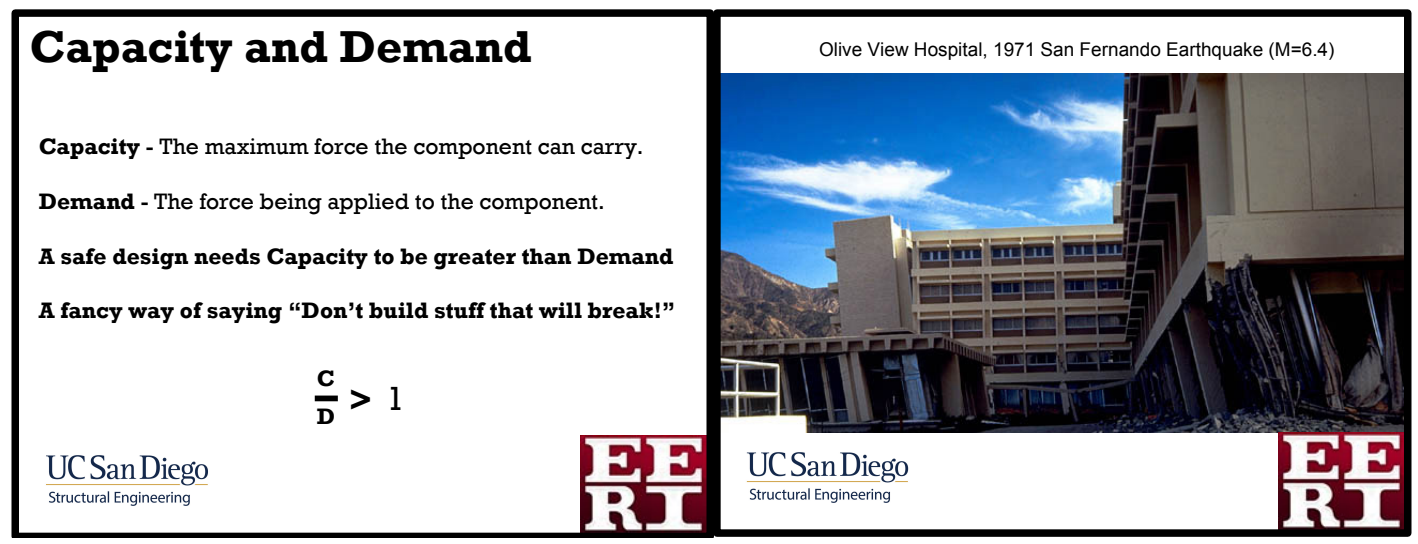

Figure 3: Example slides from high school curriculum Lecture 1

The second lecture on earthquake engineering principles gives students a detailed look into how structures can be designed to withstand earthquakes. The single degree of freedom (SDOF) model is described along with other methods of performing a dynamic analysis of a structure. Finally, students are introduced to the various structural components and systems that can be used to provide structural stability. Example slides from Lecture 2 are shown in Figure 4.

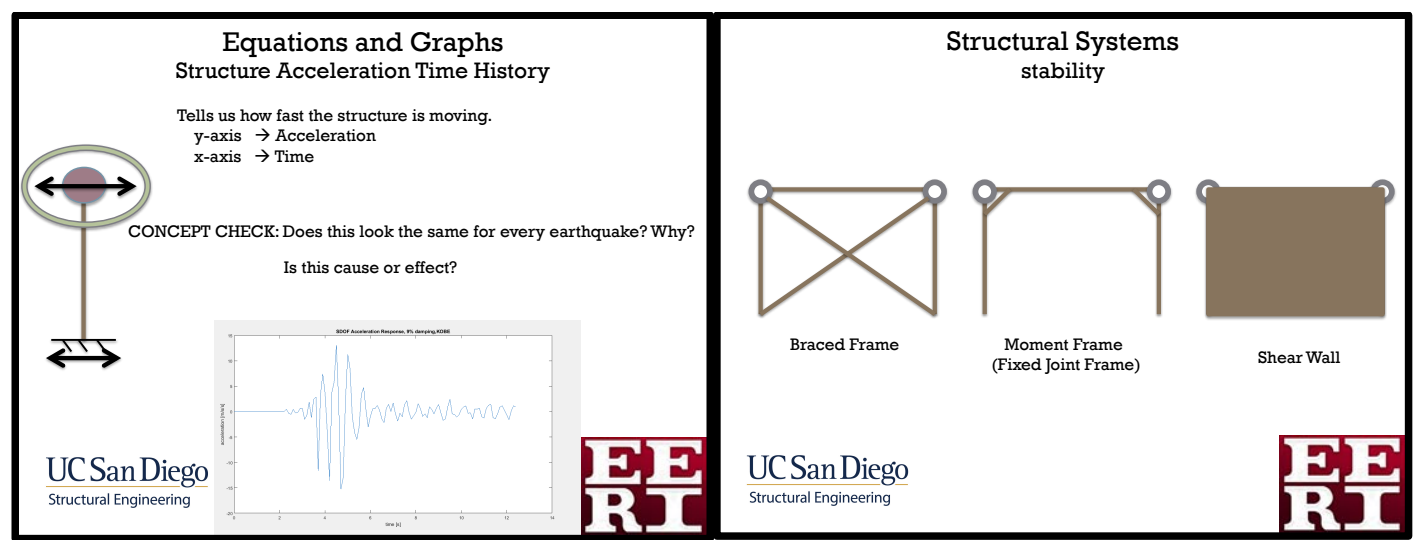

Figure 4: Example slides for high school curriculum Lecture 2

\subsubsection{Instructional Shaking Table Demonstrations}

Immediately following the second lecture, the volunteer instructors perform two demonstrations on an instructional shaking table to provide effective learning visuals for the high school students. Shaking table demonstrations have been designed to offer low-cost and exciting activities that encourage students to pursue engineering ${ }^{[16]}$. The first demonstration uses a SDOF "lollipop" model to allow students to predict the natural frequencies of several mass-stiffness systems and observe resonance behavior when the systems are subjected to sinusoidal motion on the instructional shaking table. An example of this demonstration setup is shown in Figure 5. The second demonstration is a shaking table test of an un-retrofitted balsa model structure (without a lateral force resisting system). An example of this demonstration is seen in Figure 6 . Without an LFRS, the structure fails quickly on the shaking table. This establishes the need for a well- 
designed LFRS to ensure safety of a structure and thereby serves as the motivation and introduction for the BMS design competition.

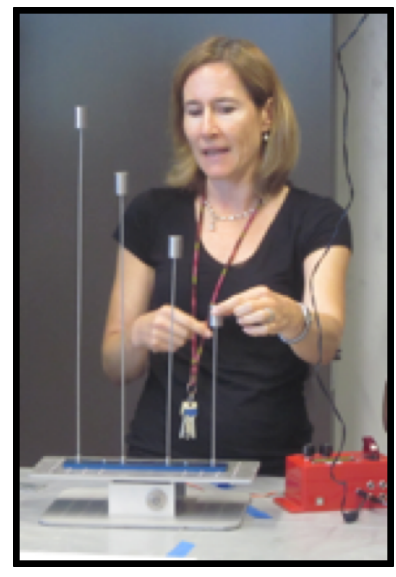

Figure 5: Resonance demonstration

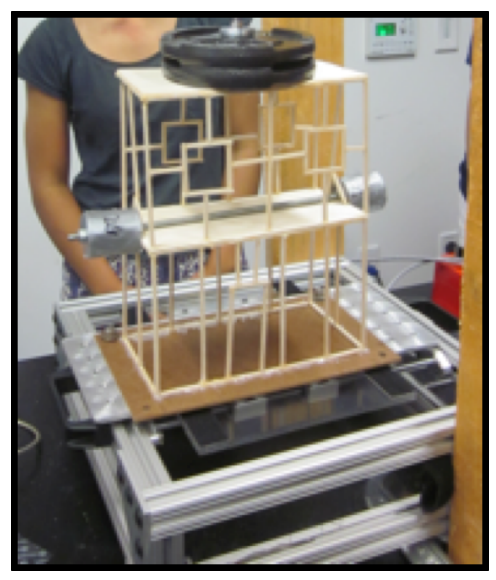

Figure 6: Testing BMS without an LFRS retrofit

\subsubsection{Concept Research Assignment}

As preparation for the design of their BMS, each team is tasked with a concept research assignment guided by a set of questions about timber construction. Specifically, these research questions require the students to investigate basic structural concepts, structural design principles, and seismic design techniques for timber structures. Through the research, the students learn about the lateral load path in structures and the techniques that are used to transfer lateral loads in timber structures. Furthermore, they discover which elements of a timber structure are most critical during an earthquake and how timber structures perform during earthquakes. Upon completion of this assignment, the students are prepared to apply the concepts of timber construction to the BMS design competition.

\subsubsection{Balsa Model Structure Design Competition}

After completion of the preliminary concept lectures, the concept research assignment, and the shaking table demonstrations, the students begin the BMS design competition. The BMS project is comprised of four main phases: design, construction, predictions, and testing. The teams are scored on a performance index that accounts for their BMS seismic performance, weight, and cost.

The project provides guidelines on the design and construction of each team's BMS. The first guideline is that each team must begin by fabricating a basic model that is identical to the model tested during the shaking table demonstration (shown in Figure 6). This ensures that each team's retrofit strategy will apply to the same basic design. When designing the retrofit, each team chooses from a controlled set of materials including diagonal braces, gusset plates, and shear wall panels, each of which has a certain cost and a purchase limit. These budget guidelines provide each team an incentive to minimize cost by thinking critically about how to design their BMS. When the team comes to consensus on their design, they purchase materials from their teacher and begin construction. All teams are provided with the same type of adhesive used to construct their BMS. The glue is not represented in the team's budget, but it is incorporated in 
the weight of each team's completed structure. This construction guideline provides each team an incentive to minimize the weight of their BMS by thinking critically about where it is necessary to use more or less adhesive.

Dynamic behavior predictions and shaking table testing follow the construction of each team's BMS. Students calculate the mass and stiffness to determine the natural frequency of their BMS. The mass is recorded using a scale, and the stiffness is calculated using the empirical Equation 1.

$$
\text { Stiffness }=K=\left(\frac{B}{115}+\frac{G}{26}\right) 325+\left(\frac{S}{60}\right) 900 \quad\left[\text { units are } \frac{N}{m}\right]
$$

where,

$$
\begin{aligned}
& \mathrm{B}=\text { total length of added braces }(\mathrm{in}) ; \\
& \mathrm{G}=\text { total number of gusset plates; } \\
& \mathrm{S}=\text { total square area of shear walls }\left(\mathrm{in}^{2}\right)
\end{aligned}
$$

Equation 1 was derived based on the performance of previously tested structures. The accuracy of this equation depends on the symmetry of the structure and is still under investigation modifications are expected after pilot SESI high school programs are completed (see Section 3).

Once the students have calculated these parameters, they can use the response spectrum (Figure 7) to predict their structure's response. The students reference the response spectrum to determine the maximum expected acceleration that their structure will experience as a function of its natural period. It should be noted that predictions are based on applying this procedure to only the first of the three earthquake records that their model buildings are subjected to, because some structures may fail on the first test.

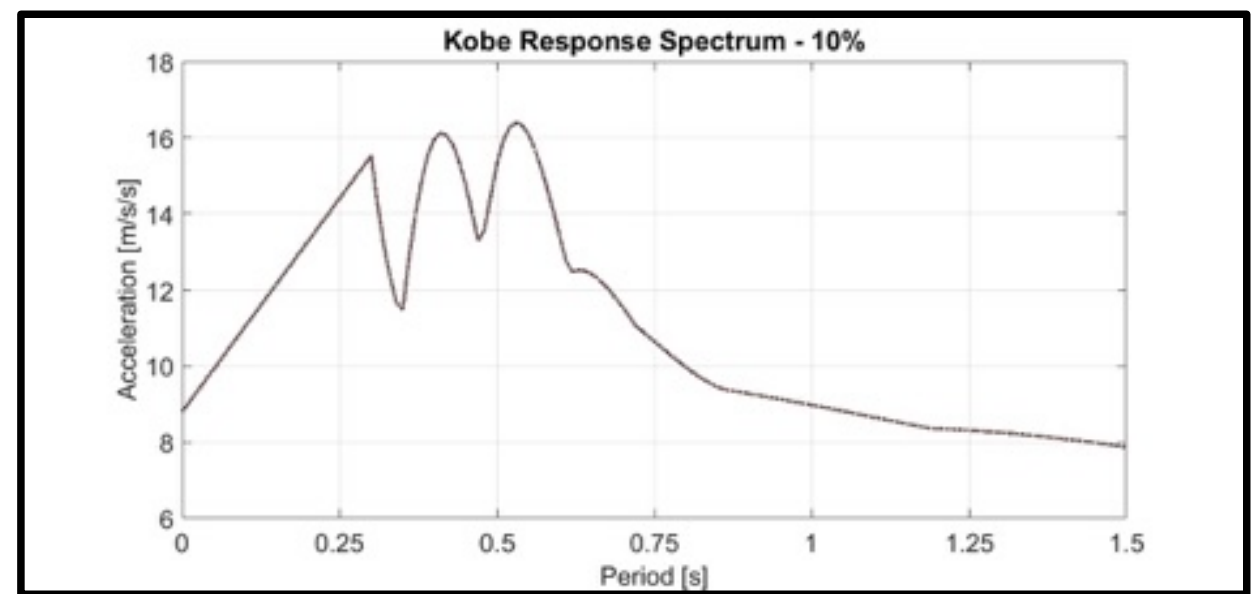

Figure 7: Calculated acceleration response spectrum

Once predictions are made and recorded, each team's BMS is tested under the three different earthquake records or until failure. While testing, an accelerometer records the BMS acceleration at the top of the structure. This recording is used to determine the accuracy of each team's predictions. Upon the completion of the shaking table testing, each team is scored based on the performance index (PI) as shown in Equation 2. 


$$
\mathrm{PI}=\frac{25 \mathrm{~N}^{1.5}}{\mathrm{WC}^{2.0}}
$$

where,

$$
\begin{aligned}
& \mathrm{N}=\text { Performance Factor }=\text { Number of Earthquakes Survived (up to three) } \\
& \mathrm{W}=\text { Weight Factor }=(\text { mass }[\text { grams }] / 225) ; \\
& \mathrm{C}=\text { Cost Factor }=(\text { cost }[\text { Dollars }] / 2500) .
\end{aligned}
$$

The Weight Factor includes an inverse factor of 225 to normalize each team's BMS with respect to previous structures tested. Also, the Cost Factor includes an inverse factor of 2500 to normalize each team's cost with respect to the overall budget (the Cost Factor will always be less than or equal to 1.0). The highest PI score determines the winner of the BMS design competition.

\subsubsection{Timeline}

Table 2 describes the sequence of visits for the SESI high school curriculum. Each visit is designed for one 60-minute class period. The time interval between each visit is flexible and is chosen to best fit in the high school classroom's overall schedule. The SESI high school curriculum can be completed in four site visits, but additional visits can be scheduled based on

\begin{tabular}{|c|c|c|c|c|}
\hline Visit & 1 & 2 & 3 & 4 \\
\hline Activity & - $\quad$ Lecture 1 & $\begin{array}{ll}\text { - } & \text { Lecture } 2 \\
\text { - } & \text { Demonstrations }\end{array}$ & $\begin{array}{l}\text { Design and } \\
\text { Construction check }\end{array}$ & $\begin{array}{ll}\text { - } & \text { Prediction Exercise } \\
\text { - } & \text { Shake Table Testing }\end{array}$ \\
\hline
\end{tabular}
the whether the high school class/teacher has time in their syllabus to allow for extra visits as well the availability of the volunteer instructors (university students and professional engineers).

Table 2: Suggested timeline for the high school curriculum

\section{Broad Implementation of EERI SESI Curriculum}

EERI is a membership organization that draws from its nearly 3,000 members to achieve its mission of reducing earthquake risks. This SESI classroom outreach program provides a way for members to share their expertise and enthusiasm with members of the public. It utilizes the existing members of both EERI Student Chapters ${ }^{[17]}$ and EERI Regional Chapters ${ }^{[18]}$ to complete lesson delivery in their region. As of January 2016 EERI has more than 60 student chapters at universities in the U.S. and around the world, and 13 regional chapters located in the U.S. Membership in EERI Student Chapters consists primarily of civil and geotechnical engineering students obtaining undergraduate, masters and $\mathrm{PhD}$ degrees. The regional chapter membership consists of professional engineers, geoscientists, architects, planners, public officials, and social scientists, who work as researchers, practicing professionals, educators, and government officials - all focusing on earthquake risk reduction.

The goal of engaging existing EERI chapters in delivering these lessons is to use chapter internal organizational structures and annual leadership transfer to facilitate the sustainability of this outreach program over time. Furthermore, teaching K-12 students about earthquake engineering concepts should reinforce the knowledge and skills of participating university students and young professionals. This was demonstrated in a study of student ambassadors delivering K-12 
tsunami engineering outreach lessons for the NEES program. Ambassadors experienced gains in professional skills such as teamwork, time management and oral presentations; expressed an increase in their self-perception as skilled leaders; and reported increased confidence in their ability to succeed in engineering ${ }^{[19]}$. The goal of partnering student instructors with professionals is to enhance the networking and knowledge of participating university students while also providing school teachers and administrators access to experts in earthquake risk reduction.

\subsection{Pilot Implementation}

Before launching the lessons and outreach program to all EERI chapters, two EERI student chapters piloted the curriculum during fall 2015. These pilots allowed the SESI to trial the implementation with student chapters by developing recruitment materials to generate student interest in volunteering and developing training materials to grow competency in lesson delivery. Furthermore both pilots built on existing relationships with schools with significant minority populations. While not a primary goal of the program, engaging underrepresented students in engineering certainly is a secondary goal.

\subsection{1. $4^{\text {th }}$ Grade Curriculum Implementation}

The UC Berkeley EERI Student Chapter focused on delivering the $4^{\text {th }}$ grade curriculum and leveraged the existing partnership with non-profit CRS to advertise the opportunity and recruit local $4^{\text {th }}$ grade classrooms and teachers. The first pilot took place in December 2015 at Cleveland Elementary School in Oakland, California and was delivered by an engineer who was involved in the 2013 lesson development with CRS (Figure 8). Four new volunteer students shadowed the engineer, observing the lesson and engaging with the elementary students during the hands-on components of the design process. Before the visit, the volunteer student instructors participated in a kick-off meeting where they familiarized themselves with the materials, learned how to operate the electronic shaking tables, and reviewed the curriculum. The lesson delivery was also recorded as a video that can be used to help train new volunteer student instructors in the future. In early 2016, the shadowing student instructors from the first pilot will form groups of two to deliver the lessons on their own in other classrooms. These new volunteers will deliver the lesson to four to eight classrooms in 2016. The student chapter also has recruited more volunteer

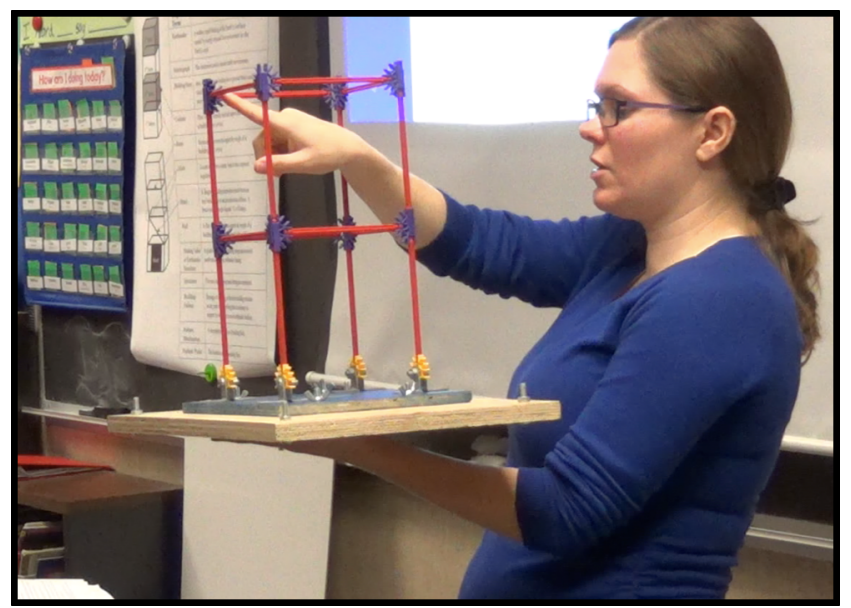

Figure 8: Fall 2015 Pilot of $4^{\text {th }}$ Grade Curriculum student instructors who will participate in a similar kick-off meeting to introduce them to the lesson, review the lesson curriculum, watch the pre-recorded video, and then shadow moreexperienced instructors in an actual classroom visit. By this apprenticeship process the UC Berkeley EERI student chapter will develop a cadre of experienced student instructors who can continue delivering the lesson in local classrooms in 2016 and beyond. 
Further pilots are planned for Spring 2016 at Stanford University, and in Fall 2016 with the EERI Utah Regional Chapter ${ }^{[20]}$. They will use a similar training and implementation model.

\subsubsection{High School Curriculum Implementation}

The SESI high school curriculum was also piloted during fall 2015 in a physics class at Westview High School in San Diego, California. Two students and a professor from the Structural Engineering department at UC San Diego implemented it. The high school teacher was already exposed to the curriculum after participating as a teacher fellow during the COSMOS program where the curriculum was originally developed. This provided a classroom setting well suited to serve as the pilot. Westview High School allows for open enrollment in their courses, thereby allowing students of any grade level to take physics. This gave the teaching team a unique opportunity to observe how students of varying ages and backgrounds interact with the curriculum.

To deliver the curriculum, the volunteer team visited the classroom four times. The first two visits included teaching, demonstrations, and the introduction of the design competition. A third visit was used to check the construction process and to explain how the students would analyze their structures and predict their behavior. During the fourth visit, the structures were tested and the winning team was identified. Overall, the students showed creativity and critical thinking in the design of their structures. However, some teams overlooked important design concepts and most teams used close to the maximum limit of materials. In terms of the testing results, five structures failed on the first ground motion, three structures failed on the second ground motion, and two structures passed all three tests.

The teaching team made small modifications to the curriculum based on observations and feedback from the first pilot and implemented a second pilot with the same teacher and high school during winter 2016. The goal for the pilot was to ensure that the students build with all design concepts in mind while also focusing on an efficient use of materials. Furthermore, improvements to the mathematical models that the students use to predict their structure's behavior were evaluated. The volunteer team was pleased with the enthusiasm and creativity that each team of students showed towards their designs and looks forward to continuing the partnership as the curriculum evolves. The teacher and students required additional class time outside the four visits to ensure effective completion of the project for design, construction time, research, and prediction activities. This revealed that additional documentation is necessary to mentor the high school teachers during the times the volunteer instructors are not in the classrooms.

The team is gathering feedback from both pilots at Westview High School to improve the curriculum documentation and finalize training tools. While the curriculum was successfully integrated throughout a semester-long standard physics class, it did require significant teacher involvement and willingness to integrate the project at appropriate times in their already-busy curriculum. Therefore, the teacher suggested that the project could be more easily integrated as a capstone project in an AP Physics class once they complete their AP Physics exam, typically in May. A final pilot at in three AP Physics courses, two of which are at a different school district, are being implemented during spring 2016. 
As these improvements are being made, the UC San Diego team is making preparations to train additional volunteers and expand the curriculum into more San Diego schools. The team is currently recruiting university students and local professional engineers from EERI student and professional chapters to broaden the number of available instructors and support a greater number of partnerships with local schools in the near future.

\section{Future Plans}

In spring 2016, the EERI SESI Classroom and Education Subcommittee is implementing an assessment to allow teachers to provide feedback on the curriculum and delivery by these pilot instructor teams. The assessment form will attempt to gain formative feedback along with the teacher's interpretation of student learning gains. Assessment approaches to consider include surveys to teachers, surveys to volunteers (professionals and students), and surveys of students.

The surveys will be modeled on the assessment form used by the NEES@Berkeley program ${ }^{[13]}$. Results will be evaluated in Summer 2016 by members of the two pilots and the SESI Classroom and Education Subcommittee to determine if changes need to be made before launching the program to other locations.

Following the completion of these pilots, during summer 2016, the SESI working group will advocate adoption of the tool kits by additional chapters and members, and support initiation of educational program development in more regions. The student chapters that piloted the program in 2015 will be used to train new student chapters on outreach implementation. We will also partner with EERI's Student Leadership Council in the recruitment, training and delivery of the outreach program and use a process of internal university student chapter recruitment to expand the pilot locations to a broader region.

This second phase of implementation of the educational programs/activities involves expanding from the pilot implementation to larger groups of chapters. This involves working with the future EERI student and professional chapters to plan for sustainability (within chapters, sharing with other educational partners, and also by teachers who can self-deliver lessons). A plan for broader dissemination (if funding or interest declines) will be developed, as well as a plan for equipment maintenance.

Ongoing assessment of educational programs and activities will occur resulting in improvements to tool kit lessons and delivery strategies. Once the $4^{\text {th }}$ grade and high school structures curricula are well developed, a possible future addition to classroom outreach could be the tsunami modules developed by the NEES@Oregon education and outreach team $\left.{ }^{[21}\right]$.

\section{Conclusions}

The EERI SESI program is ambitious but the subcommittees are making progress toward their goals. Policy statements have been drafted on mitigation of nonstructural hazards in schools and removal of the risk of unreinforced masonry schools in moderate and high seismic regions. A multi-state subcommittee of experts is identifying schools vulnerable to tsunamis in California, Washington, Oregon, Hawaii, and Alaska and is planning to share best practices for tsunami 
mitigation to at-risk schools. Another subcommittee is evaluating and comparing various approaches used by school districts across the country to screen and identify buildings susceptible to damage during earthquakes and develop a series of example approaches to share with other school districts that have not yet started to screen or evaluate their building inventory. The Classroom and Education Subcommittee has developed an engineering curriculum that meets $21^{\text {st }}$ Century education standards while engaging the students in an exciting project-based learning method.

The outreach program has generated enthusiastic response from several EERI student chapters that have successfully piloted the curriculum in several elementary schools and high schools. The goal by July 2017, is that at least 200 members from 20 EERI Professional and Student Chapters will be conducting classroom lessons and outreach activities from a selected list of vetted existing, high quality, and standards-based modules at 100 schools across the U.S. to teach about earthquake hazards, engineering principles, and risk reduction practices. These activities will be an entry point for SESI members to talk to students, teachers, administrators and parents about their seismic safety.

As the program moves forward it faces several challenges. Perhaps the most daunting challenge is funding. Although salary costs are minimized by the use of volunteers, each student chapter has start-up costs. An educational shaking table costs between $\$ 3000$ and $\$ 4000$ and a set of $\mathrm{K}^{\prime} \mathrm{Nex}^{\mathrm{TM}}$ for six design teams costs close to $\$ 400$. The balsa wood, glue, and duct tape used in the high school curriculum are not reusable, thus these are ongoing materials costs. SESI has considered writing grants to non-profits and corporations, and asking engineering firms to sponsor student chapters. The effort to create university partnerships with local schools will be an ongoing critical focus in SESI's mission to promote earthquake safety in schools. SESI has yet to develop a reliable strategy for recruiting elementary and high schools to participate. At the present time collaborations are based on pre-existing connections between teachers and EERI members. The goal is to develop simple brochures and letters of invitation to expand the program.

Another challenge is identifying regions that have both a strong and active student chapter and professional chapter. This program really works best where a professional is available to mentor students and to serve as an expert who can provide information to school administrators, teachers, parents, and others who wish to advocate for mitigating seismic risks. In locations where there are strong EERI professional chapters but not EERI student chapters, other complementary student organizations such as for example the American Society of Civil Engineers or the Society of Women Engineers can be recruited. Finally, training of new student and professional members requires further development. The apprenticeship model is attractive for chapters that already have robust outreach programs; however, as new student and professional chapters around the country volunteer to deliver the curriculum, EERI needs to develop a model to address their needs. One suggestion has been to run workshops at the EERI Annual Meeting.

Earthquake risk to school buildings needs to be understood by a variety of groups. In order to implement mitigation strategies, a clear understanding not only of the technical issues but also the economic, social, and political implications of the consequences of earthquakes is necessary. 
This paper describes a grass-roots, bottoms up approach to improve earthquake safety for school buildings by engaging K-12 students and teachers in educational activities that will serve as an entry point for EERI SESI members to talk to students, teachers, administrators and parents about their seismic safety. This is in support of the ultimate goal of the SESI initiative, which is to help communities and school districts decide which risks are acceptable or not, and to provide the tools and resources required to help these stakeholders properly evaluate and mitigate those risks $^{[3]}$.

\section{Acknowledgements}

This work was partially funded by the National Science Foundation (NSF) through the George E. Brown, Jr. Network for Earthquake Engineering Simulation program (CMMI-0927178). The findings, statements and opinions presented in this paper are those of the authors and do not necessarily represent those of the NSF. Special thanks to the following students and young professionals who were instrumental in developing pilot documentation and implementing the pilots at various local classrooms: Alexander Lee, James Mallard, Tiffany La, Eric Babin, Fredrick Ransom, Torrey Bolden, Faith Silva, Marissa Shea, Jia Shen, and Barbara Simpson. Thanks also to members of the SESI Classroom Subcommittee who are helping to further launch this curriculum in 2016, including: Eduardo Vega, Vincente Pericoli, Ivan Wong, and Barry Welliver.

\section{References}

[1] U.S. Census Bureau. (2012). Statistical Abstract of the United States (131st Edition), Section 4, Education. Retrieved from https://www.census.gov/library/publications/2011/compendia/statab/131ed/education.html

[2] Wolf, E. C., \& Yumei Wang, P. E. (2014). URM-Free By 2033: Toward A National Safe Schools Agenda. Seismic Hazard Design Issues in the Central United States, 15.

[3] NEHRP ACHER (National Earthquake Hazards Reduction Program Advisory Committee on Earthquake Hazards Reduction). (2012). Effectiveness of the National Earthquake Hazards Reduction Program. http://www.nehrp.gov/pdf/2012ACEHRReport.pdf

[4] EERI, 2016. "School Earthquake Safety Initiative," Earthquake Engineering Research Institute, available at: https://www.eeri.org/schools/

[5] EERIa. 2015. 2015 SESI Strategic Action Plan. https:/www.eeri.org/projects/schools/

[6] Jones, L. M., \& Benthien, M. (2011). Preparing for a "Big One": the great southern California ShakeOut. Earthquake Spectra, 27(2), 575-595.

[7] Doyle, K., Van Den Einde, L., French, C. W., Tremayne, H. A., \& Brophy, S. P. (2013). "Hands-On” experiential tools to introduce math, science and engineering concepts to K-16 students (Research to Practice), 120th ASEE Conference and Exposition, Atlanta, GA. http://www.asee.org/public/conferences/20/papers/7191/view

[8] NEES@Berkeley, 2016. “NEES@Berkeley: Education and Outeach,” University of California, Berkeley, available at: http://nees.berkeley.edu/Education/

[9] PEER, 2016. "PEER: K-12 Education," Pacific Earthquake Engineering Research Center, University of California, Berkeley, available at: http://peer.berkeley.edu/education/k12 education.html.

[10] CRS, 2016. “Community Resources for Science: Website Homepage," Community Resources for Science, available at: http://www.crscience.org/

[11] NGSS Lead States. (2013). Next Generation Science Standards: For States, By States. Retrieved from http://www.nextgenscience.org/ 
[12] Tremayne, H., 2012. “K'NEX Earthquake Engineering Program for 4th \& 6th Grade Students.” Network for Earthquake Engineering Simulation, available at: https://nees.org/resources/5363. Accessed January 2016.

[13] PEER, 2014. "2014 Teacher Evaluation of Program,” Pacific Earthquake Engineering Research Center, University of California, Berkeley, available at: https://peercenter.wufoo.com/forms/2014-teacher-evaluationof-program/

[14] EERIb, 2016. "School Earthquake Safety Initiative: Classroom Education and Outreach, $4^{\text {th }}$ Grade Lessons," Earthquake Engineering Research Institute, available at: https://www.eeri.org/projects/schools/subcommittees/\#education

[15] Van Den Einde, L, and Lee, S., 2011, "Exchange - Experiential Earthquake Engineering Education for High School Students through The California State Summer School for Mathematics \& Science", American Society of Engineering Education (ASEE) Annual Meeting, Vancouver, Canada, June 26-29.

[16] Van Den Einde, L., 2014, "Development of Earthquake Engineering Curriculum for High School Students Using Low-Cost Shake Tables", Tenth U.S. National Conference on Earthquake Engineering Frontiers of Earthquake Engineering, July 21-25, Anchorage, Alaska.

[17] EERIc, 2016. "EERI Student Chapters," Earthquake Engineering Research Institute, available at: https://www.eeri.org/about-eeri/student-chapters/

[18] EERId, 2016. "EERI Regional Chapters," Earthquake Engineering Research Institute, available at: https://www.eeri.org/about-eeri/regional-chapters/

[19] Anagnos, T., Lyman-Holt, A., Marin, C., Momsen, E. (2014). Impact of Engineering Ambassador Programs on Student Development, J. STEM Education: Innovations and Research, 15(3).

[20] EERIe, 2016. "EERI Utah Chapter," Earthquake Engineering Research Institute, available at: https://utah.eeri.org/

[21] Lyman-Holt, A. L. \& Robichaux, L. C. (2013). Waves of engineering: Using a mini-wave flume to foster engineering literacy, 120th ASEE Annual Conf., Atlanta, GA 